\title{
Elderly hospitalization and the New-type Rural Cooperative Medical Scheme (NCMS) in China: multi-stage cross-sectional surveys of Jiangxi province
}

Bingbing Pan ${ }^{1}$, Zhaokang Yuan ${ }^{1}$, Jiaojiao Zou' ${ }^{1}$, Daniel M. Cook ${ }^{2}$ and Wei Yang ${ }^{1,2^{*}}$

\begin{abstract}
Background: Studies assessing the impacts of China's New-type Rural Cooperative Medical Scheme (NCMS) reform of 2003 among rural elderly have been limited.

Method: Multistage stratified cluster sampling household surveys of 1838, 1924, 1879, 1888, 1890 and 1896 households from 27 villages in Jiangxi province were conducted in 2003/2004, 2006, 2008, 2010, 2012 and 2014. Data from older adults age 65 and above were analyzed. Weighted logistic regression was applied to find factors of elderly hospitalization services.

Results: Since 2003, hospitalization rates for elderly increased, while rates of patients leaving against medical advice and patients avoiding the hospital decreased $(P<0.05)$. Factors associated with a higher likelihood of reporting hospitalization in the past year for elderly were the per-capita financial level $V$ in 2012 for NCMS (Adjusted Odds Ratios [aOR]: 2.295), the level VI in 2014 (aOR: 3.045) versus the level I in 2003 and chronic disease (aOR: 2.089) versus not having a chronic disease. Lower rate of elderly left against medical advice was associated with the financial level V in 2012 (aOR: 0.099) versus the level I. The higher rate of hospital avoidance was associated with chronic disease status (aOR: 5.759) versus not having a chronic disease, while the lower rate was associated with the financial level VI in 2014 (aOR: 0.143) versus the level I. Among reporting reasons for elderly hospital avoidance, the cost-related reasons just dropped slightly over the years.

Conclusions: NCMS improved access to health services for older adults. The utilization of hospitalization services for rural elderly increased gradually, but cost-related barriers remained the primary reporting barrier to accessing hospitalization services.
\end{abstract}

Keywords: Elderly, Utilization of health services, New-type rural cooperative medical scheme (NCMS), Rural health, China

Abbreviations: aOR, Adjusted Odds Ratios; CMS, Traditional Cooperative Medical Scheme; cOR, Crude Odds Ratio; NCMS, New-type Rural Cooperative Medical Scheme

\footnotetext{
*Correspondence: weiyang@unr.edu

${ }^{1}$ School of Public Health, Nanchang University, Nanchang, People's Republic

of China

${ }^{2}$ School of Community Health Sciences, University of Nevada, Reno, USA
} 


\section{Background}

With the developing global economy and the gradual extension of human life expectancy, the aging population has become a significant public health problem worldwide [1]. The world is aging rapidly, nearly 60 countries of which have become ageing countries [2]. According to the standard of age composition from the United Nations, a society is aged if the population of 65 years old and above is more than $7 \%$ of the total population [3]. The China Statistical Bureau reports that 88 million people in China were over 65 years old in the year 2000, accounting for $7.0 \%$ of the total population, meaning that China has become an aging country [4]. Many researchers have worked on the demands and utilization of health services [5], the equity of health services [3], and Fall risk-increasing drugs and falls [6] by the elderly. Older adults are more likely to suffer from disease and need hospitalization more urgently [5, 7], resulting in a larger increase of both direct and indirect medical care costs [3]. Most nations have established medical insurance schemes to reduce high medical expenses for individuals. Government health care finance policy has affected the utilization of health services in the United States [8], Korea [9], Vietnam [10], Singapore [11] and elsewhere.

China has struggled to establish a successful medical insurance scheme for several years. Based on the People's Commune system, the traditional Cooperative medical scheme (CMS) of China was thriving in the 1950s but after a recession with the people's commune system collapse in 1980s, less than $5 \%$ of farmers were covered by health insurance in the late 1990s [12]. Soon, the burden of disease was increasing poverty across rural China, and over $30 \%$ of the rural population who were not presenting for hospitalization despite physician orders due to economical difficulty in 2003 [13]. Meanwhile, the aging population in China has continued to increase, and about $70 \%$ of elderly population who need specialized health services live in rural areas [3]. In response to those situations, the Chinese government implemented the New-type rural cooperative medical scheme (NCMS) in 2003, which provided increasing funding for hospitalization-based medical services among people living in rural area. NCMS is funded by individuals, collectives and government together, and is organized, guided and supported by government. Farmers are allowed to participate voluntarily. The major goal of NCMS is to solve the problem of poverty caused by diseases which require hospitalization services.

Jiangxi province provides a typical example of the NCMS implementation. In Jiangxi province: 1) the percapita financing level of NCMS had increased gradually from 30 Yuan in the first years, including cost sharing (consisting of 20 Yuan per-person per-year from government and 10 Yuan each person from individuals), to 370 Yuan in 2014 (320 Yuan from government and 70 Yuan from individuals); 2) risk pooling is based on the county level. The hospitalization reimbursement proportion increased each year as well. In 2003, the reimbursement rate for hospitalization in Jiangxi province at designated medical institutions varied by hospital levels, with townships at $60 \%$, counties at $40 \%$, higher level than county at $30 \%$ and non-designated hospitals at $0 \%$, in 2003 , increasing to $90,80,50$, and $35 \%$, respectively in 2014. 3) The coverage of NCMS has been over $90 \%$ since 2008 [14].

Several studies have reported evidenced that patients who had participated in NCMS were more likely to look for health care services [15-18]. Zou [19] demonstrated that NCMS improved the utilization of hospitalization services for rural residents. Yu [20] reported that outpatient service utilization has not significantly changed under NCMS, while utilization of hospitalization service has increased. Babiarz [21] showed an increase of $5 \%$ in village clinic use was associated with participation in NCMS, but no change in overall medical care use. As well, out of pocket medical cost went down by $19 \%$ and exposure to financial risk fell by 24-63\%. In contrast, one study demonstrated that the effects of NCMS are limited [22]. Early studies reported primary analysis of the impacts of NCMS on the utilization of hospitalization service in population of all ages, but little has been known about the impacts on elderly people. Nevertheless, the elderly who are in urgent demand of health service and have no economical sources should be far more affected by NCMS. In addition, some studies were out-of-date in design or lacked vertical comparisons.

Hence, this article specifically focused on elderly hospitalization from baseline (2003/2004) before the NCMS implemented, to 2014 when its coverage expanded to almost all in rural areas of Jiangxi province, China. Hospitalization was selected to measure the utilization of medical service, for the poor elderly should be far more subjected to the high hospitalization expense; three indexes, including 1) the rate of hospitalization, 2) left against medical advice and 3) hospital avoidance for elderly were used as proxy to measure hospitalization services utilization in our study [19]. Weighted data intended to make the sample, which was derived from complex sampling methods [23], better represent the population of elderly in Jiangxi province. This article is to attract more attention to the rural elderly and to evaluate the implementation effects of NCMS in Jiangxi province, providing a policy basis for improving the Health Care System Reform. 


\section{Methods}

\section{Data collection}

These materials were collected from six household surveys conducted at base-line $(2003 / 2004)$ before the NCMS implemented and the five follow-up surveys (2006, 2008, 2010, 2012, and 2014) after the NCMS implementation. All counties (70) in Jiangxi province were divided into three tiers according to the average income sorted low from high. County of Xiushui among the low-income level tier, county of Wuyuan among middle income-level tier, and county of Luxi among high income-level tier were selected from pilot counties chosen by government. Using a multistage stratified random cluster sampling method, three townships were randomly selected from each sample county (total of nine townships), three administrative villages were randomly selected from each sample township (total of 27 administrative villages). At last we had investigated approximately all of households in each sample administrative village.

The questionnaires were completed by asking the head of the household about the information from each family member (another family member who is over 18 years old will be interviewed if the head of the household isn't at home). The questionnaire, including three part (part of general information for the farmer family, part of farmer family health, part of the utilization of medical services, medical costs, and reimbursement fees), was recommended by the Ministry of Health of China and adjusted slightly in the light of the actual situation and the purpose of the study (Additional files 1 and 2). Data on older adults (aged 65 and above) were separated from aggregate data. We had $100 \%$ response rates in all surveys, probably due to the support of local governments. To ensure comparability, we had followed up the same villages in six surveys.

\section{Data weighting method [23-25]}

The related data of participants were weighted to ensure the sample, which come from complex sampling, better represent the population of elderly in Jiangxi province by reduced bias.

The base weight $\mathrm{W}_{\text {base }}=\mathrm{W}_{1} \times \mathrm{W}_{2 \mid 1} \times \mathrm{W}_{3 \mid 2,1}$. $\mathrm{W}_{\text {base }}$ is the base sampling weight of individual, $W_{1}$ is sampling weight of stage one, $W_{2 \mid 1}$ is the sampling weight of stage two, $W_{3 \mid 2,1}$ is the sampling weight of stage three. $W_{i}$ is the sampling weight of individual and is equal to the reciprocal of individual sampling probability $\mathrm{Pi}$, meaning $\mathrm{W}_{\mathrm{i}}=1 / \mathrm{P}$.

The adjust weight: $W_{a j_{-} i j}=N_{i j} / \sum_{m=1}^{n_{i j}} W_{i j m}, w_{a d j-i j}$ is the adjusted weight for individual, $N_{i j}$ refers to the individual ensemble of certain category after cross classification of important auxiliary variables such as gender $(i=1,2)$ and age $(j=1,2,3), \sum_{m=1}^{n_{i j}} W_{i j m}$ is the base weight sum of certain group after cross classification.

The final weight of individual $W=W_{\text {base }} \times W a d j \_i j=$ $\mathrm{W}_{1} \times \mathrm{W}_{2 \mid 1} \times \mathrm{W}_{3 \mid 2,1} \times N_{i j} / \sum_{m=1}^{n_{i j}} W_{i j m}$

\section{Sample size estimate}

The sample size is estimated by the formula [26]

$$
\mathrm{n}=\frac{z_{\alpha / 2}^{2} \times p(1-p)}{\delta^{2}}
$$

Where $\mathrm{n}$ is sample size and $\mathrm{p}$ is the hospitalization rate for base-line survey $(p \approx 5 \%) ; \mathrm{Z}_{\alpha / 2}$ is normal deviate for two-tailed alternative hypothesis at a level of significance, $\alpha$ is set up as 0.05 , So $Z_{0.05 / 2}=1.96 ; \delta$ is the desired level of margin of error (usually 0.01). So we manually calculated out $n=1825$. Owing to our research having used cluster sampling method as well, the sampling error is larger than simple random sampling, so it's better to investigate more by plus $0.5 \mathrm{n}$ [27], finally we got a minimal sample size for cluster sampling as $\mathrm{n}_{1}$, thus $\mathrm{n}_{1}=\mathrm{n}+0.5 \mathrm{n}=2737.5 \approx 2738$, which is far below the actual sample size (7500 ) for six years (Table 1).

\section{Indexes construction}

The hospitalization rate of elderly means the rate of the elderly in hospitalization as a result of disease compared to the total number of elderly respondents in the past year (\%). Hospitalization was measured by asking whether respondents received any hospitalization services in the past year.

The left against medical advice rate of elderly refers to the rate of the number of elderly who left the hospital against medical advice to the number of elderly hospitalization in the past year (\%). Left against medical advice was measured by asking whether there was a time in the past year when a doctor advised the respondent to stay in the hospital, but he or she left nonetheless.

The rate of elderly hospital avoidance means the rate of the number of elderly people who should receive hospitalization services but did not, compared to the number of those who should be hospitalized in the past year (\%). Hospital avoidance was measured by asking whether there was a time in the past year when a doctor thought the respondent should receive hospitalization services but the patient was never admitted.

If a patient had more than one episode of hospitalization or left against medical advice, or chose hospital avoidance, she/he was only counted once in calculating the three indexes. 
Table 1 Description of the sample characteristics after data weighted from 2003/2004 to 2014 [percent, estimator (95 \%.Cl.)]

\begin{tabular}{|c|c|c|c|c|c|c|}
\hline Variable & $2003 / 2004$ & 2006 & 2008 & 2010 & 2012 & 2014 \\
\hline \multicolumn{7}{|l|}{ Overall sample } \\
\hline Total responses $(n)^{a}$ & 7792 & 8080 & 9586 & 7506 & 7857 & 7810 \\
\hline Total responses (n) & 850519 & 1049234 & 1110086 & 1127340 & 1126276 & 1464991 \\
\hline Household (n) ${ }^{\text {a }}$ & 1838 & 1924 & 1879 & 1888 & 1890 & 1896 \\
\hline Household (n) & 166452 & 219186 & 202718 & 253229 & 239076 & 307098 \\
\hline 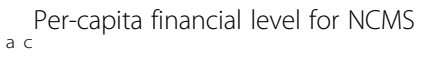 & 43 & 66 & 123 & 173 & 306 & 370 \\
\hline Per-capita hospitalization cost ${ }^{c}$ & $\begin{array}{l}3931.15(1755.74 \\
6106.57)\end{array}$ & $\begin{array}{l}4368.88(2411.44 \\
6326.27)\end{array}$ & $\begin{array}{l}5182.37(3601.72, \\
6763.03)\end{array}$ & $\begin{array}{l}4256.32 \text { (3201.31, } \\
5311.32)\end{array}$ & $\begin{array}{l}6072.76(5243.59, \\
6901.92)\end{array}$ & $7245.03(6580.56,7909.52)$ \\
\hline \multicolumn{7}{|l|}{ Sex } \\
\hline Male & $52.17(49.51,54.82)$ & $52.39(49.92,54.85)$ & $51.88(50.99,52.77)$ & $51.83(50.91,52.75)$ & $51.74(50.85,52.63)$ & $51.78(50.79,52.78)$ \\
\hline Female & $47.83(45.18,50.49)$ & $47.61(45.15,50.08)$ & $48.12(47.23,49.01)$ & $48.17(47.25,49.09)$ & $48.26(47.37,49.15)$ & $48.22(47.22,49.21)$ \\
\hline \multicolumn{7}{|l|}{ Age } \\
\hline $0 \sim 64$ & $93.38(90.62,95.37)$ & $93.44(90.94,95.29)$ & $92.80(89.94,94.89)$ & $92.80(90.56,94.55)$ & $92.75(91.99,93.45)$ & $91.54(89.85,92.97)$ \\
\hline $65 \sim$ & $6.62(4.63,9.38)$ & $6.56(4.71,9.06)$ & $7.20(5.11,10.05)$ & $7.20(5.45,9.44)$ & $7.25(6.55,8.01)$ & $8.46(7.03,10.15)$ \\
\hline \multicolumn{7}{|l|}{ Sample of elderly ${ }^{b}$} \\
\hline Response $(n)^{a}$ & 631 & 631 & 833 & 615 & 667 & 766 \\
\hline \multicolumn{7}{|l|}{ Sex } \\
\hline Male & $50.48(47.50,53.46)$ & $50.48(48.28,52.67)$ & $50.36(46.28,54.44)$ & $50.05(45.28,54.81)$ & $49.74(45.95,53.52)$ & $51.30(46.17,56.41)$ \\
\hline Female & $49.52(46.54,52.50)$ & $49.52(47.33,51.72)$ & $49.64(45.56,53.72)$ & $49.95(45.19,54.72)$ & $50.26(46.48,54.05)$ & $48.70(43.59,53.83)$ \\
\hline \multicolumn{7}{|l|}{ Age } \\
\hline $65 \sim$ & $60.60(57.17,63.93)$ & $62.72(56.88,68.20)$ & $65.97(59.09,72.24)$ & $67.24(59.52,74.12)$ & $68.03(55.38,78.48)$ & $63.10(55.05,70.49)$ \\
\hline $75 \sim$ & $34.77(28.53,41.57)$ & $33.35(28.16,38.98)$ & $29.30(23.85,35.41)$ & $27.90(21.00,36.03)$ & $27.13(17.68,39.22)$ & $29.68(23.48,36.74)$ \\
\hline $85 \sim$ & $4.63(1.85,11.15)$ & $3.93(2.87,5.37)$ & $4.73(2.81,7.85)$ & $4.86(3.17,7.39)$ & $4.85(3.21,7.26)$ & $7.21(4.96,10.38)$ \\
\hline \multicolumn{7}{|l|}{ Occupation } \\
\hline Farmer & $97.30(93.95,98.82)$ & $96.57(94.13,98.02)$ & $95.53(92.81,97.25)$ & $92.65(81.16,94.89)$ & $91.25(84.51,95.23)$ & $90.09(87.26,92.34)$ \\
\hline No-farmer & $2.70(1.18,6.05)$ & $3.43(1.98,5.87)$ & $4.47(2.75,7.19)$ & $7.35(3.11,16.84)$ & $8.75(4.77,15.49)$ & $9.91(7.66,12.74)$ \\
\hline \multicolumn{7}{|l|}{ Educational level } \\
\hline Illiterate & $49.80(43.80,55.80)$ & $36.78(30.15,43.95)$ & $31.03(23.15,40.18)$ & $27.23(20.29,35.49)$ & $16.43(11.81,22.40)$ & $28.74(24.46,33.44)$ \\
\hline Elementary school & $42.82(36.97,48.87)$ & $54.20(46.14,62.06)$ & $56.17(46.64,65.27)$ & $54.87(44.49,64.84)$ & $67.91(58.81,75.82)$ & $54.00(37.70,69.49)$ \\
\hline Middle school and above & $7.39(3.68,14.29)$ & $9.02(3.99,19.12)$ & $12.80(6.41,23.93)$ & $17.90(12.30,25.31)$ & $15.67(9.08,25.69)$ & $17.25(7.67,34.34)$ \\
\hline
\end{tabular}


Table 1 Description of the sample characteristics after data weighted from 2003/2004 to 2014 [percent, estimator (95\%.Cl.)] (Continued)

\begin{tabular}{|c|c|c|c|c|c|c|}
\hline Married & $64.16(54.25,72.99)$ & $54.49(50.50,58.42)$ & $62.93(51.03,73.44)$ & $59.61(52.70,66.15)$ & $62.21(58.77,65.54)$ & $64.16(57.08,70.68)$ \\
\hline Unmarried/divorced/widowed & $35.84(27.01,45.74)$ & $45.51(41.58,49.50)$ & $37.07(26.56,48.97)$ & $40.39(33.85,47.30)$ & $37.79(34.46,41.23)$ & $35.84(29.32,42.92)$ \\
\hline \multicolumn{7}{|l|}{ Labor force } \\
\hline Yes & $11.08(8.27,14.69)$ & $31.46(27.23,36.03)$ & $14.89(12.03,18.28)$ & $33.21(27.59,39.35)$ & $40.19(35.34,45.24)$ & $44.92(38.38,51.65)$ \\
\hline No & $88.92(85.31,91.73)$ & $68.54(63.97,72.77)$ & $85.11(81.72,87.97)$ & $66.79(60.65,72.41)$ & $59.81(54.76,64.66)$ & $55.08(48.35,61.62)$ \\
\hline \multicolumn{7}{|l|}{ Chronic disease } \\
\hline Yes & $25.87(21.43,30.87)$ & $23.10(15.37,33.20)$ & $25.69(17.22,36.50)$ & $31.43(27.68,35.45)$ & $22.70(19.62,26.11)$ & $29.62(24.53,35.27)$ \\
\hline No & $74.13(69.13,78.57)$ & $76.90(66.80,84.63)$ & $74.31(63.50,82.78)$ & $64.55(59.25,72.32)$ & $77.30(73.89,80.38)$ & $70.38(64.73,75.47)$ \\
\hline \multicolumn{7}{|l|}{ NCMS } \\
\hline Yes & $0.00(0.00,0.00)$ & $96.66(89.85,98.96)$ & $99.29(97.91,99.76)$ & $99.63(97.13,100.00)$ & $100.00(100.00,100.00)$ & $100.00(100.00,100.00)$ \\
\hline No & $100.00(100.00,100.00)$ & $3.34(1.04,10.15)$ & $0.71(0.24,2.09)$ & $0.36(0.05,2.87)$ & $0.00(0.00,0.00)$ & $0.00(0.00,0.00)$ \\
\hline $\begin{array}{l}\text { Per-capita income per year } \\
{\left[\text { mean, estimator }(95 \% \text { \%.Cl.) }]^{c}\right.}\end{array}$ & $\begin{array}{l}3882.56(3031.80 \\
4733.33)\end{array}$ & $\begin{array}{l}8589.0(7055.90 \\
10122.21)\end{array}$ & $\begin{array}{l}6339.38(4278.85 \\
8399.91)\end{array}$ & $\begin{array}{l}8443.24(7860.20 \\
9026.29)\end{array}$ & $\begin{array}{l}8375.49(7070.40 \\
9680.57)\end{array}$ & $\begin{array}{l}15653.19(6814.34 \\
24492.04)\end{array}$ \\
\hline
\end{tabular}

Without weighted the data

Elderly: aged 65 and above

c Per-capita financial level, Per-capita hospitalization cost and Annual per capita household income were inflated to the year of 2014 using rural consumer price index; their units are RMB (Yuan) 


\section{The quality and representativeness of the data}

We used Myer's index to test the data quality, using age as the basis of the logic judgment process [28]. Myer's index should not be bigger than 60; otherwise the quality of the data was poor for us to analyze [29]. We used goodness for fit test to observe the fitting degree of the distribution of sample data and the distribution of theoretical frequency. If the test results showing no statistical significance $(P$ values $>0.05)$, the representativeness of the data cannot be regarded as poor.

The results of the Myer's index of this study from $2003 / 2004$ to 2014 were $4.00,5.12,12.02,8.52,3.54$, and 7.07 , respectively. Correspondingly, the value of $\chi^{2}$ of the test of goodness for fit of sex were 0.0014, 0.0002, $0.0005,0.1103,0.0021,0.5396, P$ values $>0.05$. Therefore, the quality and representativeness of the data cannot be regarded as poor.

\section{Data analysis}

The sample data were weighted to be representative of our target population using methods consistent with previous research [24, 25, 30-32]. Myer's index and goodness for fit test were employed to test the data quality and representativeness [28, 29]. Pearson Chi-Square test was used to compare the differences between groups. The significance level $\alpha$ was set at 0.05 . The rates of elderly hospitalization, left against medical advice and hospital avoidance were used to descript the utilization of hospitalization service. We applied weighted logistic regression to find factors of the utilization of hospitalization service. Crude Odds ratio (cOR) was conducted by bivariate logistic regression and adjusted Odds ratio (aOR) was conducted by multivariate logistic regression with stepwise technique. The inclusion criteria of stepwise in the logistic regressions model was set at $\leq 0.05$ [33]. Independent variables included per-capita financially level for NCMS (referent group = level I), sex (referent group = female), occupation (referent group $=$ farmer), educational level (referent group=illiterate), marital status (referent group $=$ married), labor force (referent group = non-labor force), chronic disease (referent group = nonchronic disease), per-capita income per year (referent group = group I). The financially level every year for NCMS was inflated into the year of 2014 using rural consumer price index [4] and used as the proxy of effects of NCMS, for the coverage rate of NCMS for elderly has been over $95 \%$ since 2006 (see Table 1). The per capita income per year was inflated into the year of 2014 using rural consumer price index [4] and divided into five groups when sorted from low to high (group I, group II, group III, group IV, group $\mathrm{V})$, for analyzed the effects of per capita income on elderly hospitalization. Microsoft excel 2013 software was used to set up data base, weight the data and draft the figures, PASW Statistics 18.0 software to analyze the data.

\section{Results \\ Sample characteristics}

The numbers of elderly/overall sample for the six surveys before data weighted were 631/7792, 631/8080, 833/9586, 615/7506, 667/7857 and 766/7810, respectively. The proportions of elderly number to the number of overall sample of the six surveys after data weighted were $6.62,6.56,7.20,7.20,7.25$, and $8.46 \%$, respectively, which evidenced that Jiangxi province has been becoming an aging area. The prevalence of chronic disease in half year for elderly from $25.87 \%$ in 2003/2004 increased slightly to $29.62 \%$ in 2014 . After inflating the per capita income for elderly, per-capita financial level for NCMS and per-capita hospitalization cost of 2003/2004, 2006, 2008, 2010 and 2012 to 2014 levels (using the rural consumer price index), the per capita income was 15653.19 Yuan in 2014, whose annual average growth rate was $14.96 \%$; the annual average growth rate for per-capita financial level was $21.72 \%$ from $2003 / 2004$ to 2014 , for percapita hospitalization cost was $6.30 \%$. The coverage of NCMS for elderly has been over $95 \%$ since 2006 (see Table 1).

\section{Changes of hospitalization services utilization for elderly}

After weighting the data, the rates of elderly hospitalization rose from $6.67 \%$ in baseline $(2003 / 2004)$ to $18.70 \%$ in 2014 (6.39 \% in 2006, $9.43 \%$ in 2008, $10.50 \%$ in 2010 , $13.99 \%$ in 2012), the rates of elderly left against medical advice dropped from $21.59 \%$ in 2006 to $9.25 \%$ in 2014 (8.22 \% in 2008, $12.91 \%$ in 2010, $2.49 \%$ in 2012), and the rates of elderly hospital avoidance fell from $46.11 \%$ in baseline to $12.19 \%$ in 2014 (35.84 \% in 2006, $35.60 \%$ in 2008, $14.91 \%$ in 2010, $7.88 \%$ in 2012). The $\chi^{2}$ test of the three indexes showed statistical significance $(P<0.05)$. See Table 2.

\section{Bivariate analysis for the utilization of elderly hospitalization services}

The hospitalization rates of the elderly with different demographic characteristics including age, educational level, marital status and labor force, chronic disease, percapita income per-year demonstrate statistical significance $(P$ values $<0.05)$. The rates of elderly who left against medical advice and who avoided hospital with different demographic characteristics including sex, age, occupation, educational level, marital status and labor force, chronic disease, per-capita income per-year showed statistical significance (all $P$ values $<0.05$ ). See Table 2. 
Table 2 Bivariate analysis of the three indexes after data weighted [percent, estimator (95 \%.CI.)]

\begin{tabular}{|c|c|c|c|}
\hline Demographic characteristics & $\begin{array}{l}\text { The rate of elderly } \\
\text { hospitalization }\end{array}$ & $\begin{array}{l}\text { The rate of elderly leaving } \\
\text { against medical advice }\end{array}$ & $\begin{array}{l}\text { The rate of elderly } \\
\text { hospital avoidance }\end{array}$ \\
\hline \multicolumn{4}{|l|}{$\overline{\text { Year }^{\mathrm{a}}}$} \\
\hline $2003 / 2004$ & $6.67(4.51,9.76)$ & - & $46.11(13.85,82.00)$ \\
\hline 2006 & $6.39(3.20,12.36)$ & $21.59(7.82,47.19)$ & $35.84(25.05,48.29)$ \\
\hline 2008 & $9.43(7.65,11.57)$ & $8.22(2.51,23.79)$ & $35.60(19.81,55.30)$ \\
\hline 2010 & $10.50(4.50,22.59)$ & $12.91(4.73,30.70)$ & $14.91(8.56,24.69)$ \\
\hline 2012 & $13.99(10.74,18.03)$ & $2.49(0.96,6.30)$ & $7.88(2.06,25.79)$ \\
\hline 2014 & $18.70(10.50,31.09)$ & $9.25(3.49,22.30)$ & $12.19(5.99,23.23)$ \\
\hline$p^{b}$ & $p<0.001$ & $p<0.001$ & $p<0.001$ \\
\hline \multicolumn{4}{|l|}{ Sex } \\
\hline Male & $11.93(9.56,14.80)$ & $11.28(6.14,19.81)$ & $19.14(15.94,22.80)$ \\
\hline Female & $11.98(10.35,13.83)$ & $7.19(2.20,21.05)$ & $21.97(18.02,26.49)$ \\
\hline$p^{b}$ & $p>0.050$ & $p<0.001$ & $p<0.001$ \\
\hline \multicolumn{4}{|l|}{ Age } \\
\hline $65 \sim$ & $11.39(8.39,15.28)$ & $11.51(6.55,19.45)$ & $18.78(11.92,28.32)$ \\
\hline $75 \sim$ & $13.84(10.50,18.03)$ & $4.36(1.78,10.30)$ & $22.00(15.57,30.15)$ \\
\hline $85 \sim$ & $8.24(5.21,12.80)$ & $15.11(5.72,34.32)$ & $33.76(13.38,62.72)$ \\
\hline$p^{b}$ & $p<0.001$ & $p<0.001$ & $p<0.001$ \\
\hline \multicolumn{4}{|l|}{ Occupation } \\
\hline Farmer & $13.39(5.67,28.45)$ & $9.58(5.72,15.62)$ & $21.64(17.57,26.35)$ \\
\hline No-farmer & $11.86(10.19,13.76)$ & $5.47(0.95,25.92)$ & $5.25(0.62,32.87)$ \\
\hline$p^{b}$ & $p>0.050$ & $p<0.001$ & $p<0.001$ \\
\hline \multicolumn{4}{|l|}{ Educational level } \\
\hline Illiterate & $10.93(9.56,12.46)$ & $9.41(3.22,24.47)$ & $24.39(17.73,32.56)$ \\
\hline Elementary school & $12.22(9.49,15.61)$ & $7.72(3.59,15.83)$ & $18.42(13.45,24.71)$ \\
\hline Middle school and above & $15.47(10.09,16.92)$ & $14.38(4.58,37.01)$ & $22.77(9.35,40.00)$ \\
\hline$p^{b}$ & $p<0.001$ & $p<0.001$ & $p<0.001$ \\
\hline \multicolumn{4}{|l|}{ Marital status } \\
\hline Unmarried/divorced/widowed & $9.73(7.13,13.13)$ & $7.75(3.22,17.53)$ & $30.84(18.58,46.56)$ \\
\hline Married & $13.35(11.66,15.25)$ & $9.92(5.39,17.58)$ & $14.79(6.99,28.62)$ \\
\hline$p^{b}$ & $p<0.001$ & $p<0.05$ & $p<0.001$ \\
\hline \multicolumn{4}{|l|}{ Labor force } \\
\hline Yes & $11.20(9.82,12.74)$ & $5.42(2.36,12.00)$ & $19.80(9.27,37.38)$ \\
\hline No & $13.61(10.39,17.63)$ & $11.04(6.17,18.98)$ & $21.00(16.21,26.76)$ \\
\hline$p^{b}$ & $p<0.001$ & $p<0.001$ & $p<0.001$ \\
\hline \multicolumn{4}{|l|}{ Chronic disease } \\
\hline Yes & $18.16(12.73,25.25)$ & $13.84(6.23,27.94)$ & $32.63(24.66,41.75)$ \\
\hline No & $9.69(8.51,11.01)$ & $6.09(2.52,13.98)$ & $10.31(6.75,15.44)$ \\
\hline$p^{b}$ & $p<0.001$ & $p<0.001$ & $p<0.001$ \\
\hline \multicolumn{4}{|l|}{ Per-capita income per year ${ }^{c}$} \\
\hline Group I & $10.21(7.75,13.36)$ & $2.71(0.36,17.73)$ & $29.72(22.43,38.22)$ \\
\hline Group ॥ & $9.84(7.76,12.41)$ & $23.99(10.42,46.14)$ & $30.04(16.61,48.07)$ \\
\hline Group III & $10.75(8.13,14.08)$ & $4.80(1.01,20.01)$ & $15.33(8.34,26.47)$ \\
\hline
\end{tabular}


Table 2 Bivariate analysis of the three indexes after data weighted [percent, estimator (95\%.Cl.)] (Continued)

\begin{tabular}{llll}
\hline Group IV & $13.44(10.64,16.85)$ & $7.88(2.83,20.11)$ & $20.23(14.43,27.60)$ \\
Group V & $14.60(7.53,26.41)$ & $8.36(2.36,25.65)$ & $12.01(7.75,18.13)$ \\
$\mathrm{P}^{\mathrm{b}}$ & $p<0.001$ & $p<0.001$ & $p<0.001$ \\
\hline
\end{tabular}

${ }^{a}$ The survey of leaving against medical advice started in 2006

b Pearson Chi-Square test

c The per capita income per year was inflated to the year of 2014 using rural consumer price index and divided into five groups when sorted from low to high ( $V$ is the highest)

\section{Weighted logistic regression analysis for influences} factors of the utilization of elderly hospitalization services To assign variables for the weighted logistic regression model, per-capita financial level, sex, age, occupation, educational level, marital status, labor force, and chronic disease, per capita income per year were took as independent variable, and the dependent variables were the rates of elderly hospitalization, left against medical advice and hospital avoidance. See Appendix.

Logistic regression analysis after data weighted PASW Statistics 18.0 software was employed to carry out logistic regression of complex sample. Crude Odds ratio (cOR) was conducted by bivariate logistic regression and adjusted Odds ratio (aOR) was conducted by multivariate logistic regression with with stepwise technique. In Table 3, independent variables of equation for the three indexed were displayed below.

Factors were associated with a higher likelihood of reporting hospitalization in the past year for elderly were the per-capita financial level V in 2012 (aOR: 2.295), the level VI in 2014 (aOR: 3.045) versus the level I in 2003 and chronic disease (aOR: 2.089) versus not having a chronic disease. Lower rate of elderly left against medical advice was associated with the financial level $\mathrm{V}$ in 2012 (aOR: 0.099) versus the level I. Higher rate of hospital avoidance was associated with chronic disease status (aOR: 5.759) versus not having a chronic disease, while the lower rate was associated with the financial level VI in 2014 (aOR: 0.143) versus the level I. All of the above variables in the models showed statistical significance $(P$ values $\leq 0.05)$.

\section{The analysis of reporting reasons for elderly left against} medical advice and hospital avoidance

Among the reporting reasons for elderly left against medical advice (Fig. 1) (e.g. financial difficulties, poor quality and attitudes of medical service, deciding selfrecovered and others), financial difficulties played an important role before 2010, but declined sharply in 2010 and then presented a rebound trend. In the reporting reasons of elderly hospital avoidance (Fig. 2), including financial difficulties, poor quality and attitudes of medical service, no serious illness and giving self-care and others, the proportion of financial difficulties declined slightly. But it still was the main reason in all of the years.

\section{Discussion}

In this study, the rates of elderly hospitalization, patientinitiated early discharge, and hospital avoidance have been increasing, dropping and dropping, respectively from 2003 to 2014. This reveals that the appropriate utilization of elderly hospitalization service has been facilitated in these years. The potential reason may be some health care reforms carried out in China, like NCMS. The policy had a primary aim to resolve economic barriers to hospitalization. The actual proportion of hospitalization reimbursement (the proportion of farmers' expense for hospitalization reimbursed by relevant departments to all of the expenditures) increased in Jiangxi province, from $40.55 \%$ in 2008 [34] to $55.09 \%$ in 2014 [35]. Nearly half of the hospitalization cost could be rembursed after 2008, which eased the burden of hospitalization services for a large sector of rural residents who participated in NCMS. This means participants would be more likely to be hospitalized when illness warranted, rather than cobbling together other various remedies. This is in agreement with another study that found NCMS promoted the utilization of inpatient service among the elderly [36]. Even though other health care reforms, such as public hospital reform and essential medicine reform, were carried out as well in recent years, the new systems are not without limits. Public hospital reform was brought to life among county-level hospitals in 2013 and covered $13.13 \%$ of overall counties in Jiangxi province [37]. The coverage rate of public hospital reform in Jiangxi was only $22.22 \%$ in 2014 [35]. Essential medicine reform was brought to life by the government of China in 2009 [38] and covered only the primary health care institutions (township health center, village clinic) in 2014, while the availability of hospitalization services for rural residents was overwhelmingly county-level hospitals [35]. In addition, an empirical study demonstrated that, compared to non-pilot medical institutions, the total hospitalization cost in the pilot primary health care institutions where the essential medicine reform as 
Table 3 Independent variables in the equation of the three indexes and the estimation value of OR

\begin{tabular}{|c|c|c|c|c|c|c|}
\hline \multirow[t]{2}{*}{ Variable } & \multicolumn{2}{|l|}{ Elderly hospitalization } & \multicolumn{2}{|c|}{ Elderly leaving against medical advice } & \multicolumn{2}{|c|}{ Elderly hospital avoidance } \\
\hline & COR $(95 \% . C l)$ & aOR $(95 \% . C l)$ & cOR $(95 \% . C l)$ & aOR $(95 \% . C l)$ & COR $(95 \% . C l)$ & aOR $(95 \% . C l)$ \\
\hline \multicolumn{7}{|l|}{ Per-capita financial level for NCMS ${ }^{\text {a }}$} \\
\hline Level II (2006) & $0.955(0.384,2.315)$ & $0.967(0.359,2.610)$ & - & - & $0.653(0.089,4.783)$ & $0.648(0.052,8.076)$ \\
\hline Level III (2008) & $1.457(0.956,2.222)$ & $1.456(0.847,2.504)$ & $0.325(0.080,1.316)$ & $0.229(0.033,1.607)$ & $0.646(0.059,7.105)$ & $0.495(0.021,11.912)$ \\
\hline Level IV (2010) & $1.641(0.844,3.190$ & $1.550(0.754,3.185)$ & $0.538(0.091,3.194)$ & $0.413(0.144,1.185)$ & $0.205(0.039,1.081)$ & $0.205(0.020,2.139)$ \\
\hline Level V (2012) & $2.276(1.452,3.567)^{* *}$ & $2.295(1.401,3.759)^{* *}$ & $0.093(0.022,0.389)^{* *}$ & $0.099(0.033,0.293)^{* *}$ & $0.100(0.006,1.712)$ & $0.073(0.003,1.984)$ \\
\hline Level VI (2014) & $3.219(1.187,8.732)^{*}$ & $3.045(1.183,7.834)^{*}$ & $0.370(0.115,1.188)$ & $0.407(0.102,1.618)$ & $0.162(0.047,0.556)^{*}$ & $0.143(0.024,0.875)^{*}$ \\
\hline \multicolumn{7}{|l|}{ Sex } \\
\hline Male & $0.995(0.795,1.246)$ & $0.900(0.695,1.165)$ & $0.610(0.134,2.772)$ & $1.762(0.486,6.391)$ & $0.841(0.656,1.078)$ & $1.269(0.876,1.837)$ \\
\hline \multicolumn{7}{|l|}{ Age } \\
\hline $75 \sim$ & $1.250(0.685,2.282)$ & $1.438(0.690,2.996)$ & $2.853(1.265,6.434)^{*}$ & $0.390(0.142,1.070)$ & $1.220(0.498,2.986)$ & $1.295(0.610,2.751)$ \\
\hline $85 \sim$ & $0.699(0.501,0.975)^{*}$ & $0.802(0.396,1.621)$ & $0.731(0.201,2.662)$ & $1.422(0.280,7.224)$ & $2.205(0.465,10.475)$ & $2.555(0.720,9.072)$ \\
\hline \multicolumn{7}{|l|}{ Occupation } \\
\hline No-farmer & $1.149(0.445,2.967)$ & $0.979(0.391,2.450)$ & $0.546(0.123,2.429)$ & $0.743(0.052,10.696)$ & $0.201(0.019,2.169)$ & $0.208(0.015,1.872)$ \\
\hline \multicolumn{7}{|l|}{ Educational level } \\
\hline Elementary school & $1.135(0.829,1.555)$ & $1.019(0.849,1.222)$ & $0.806(0.444,1.463)$ & $1.357(0.421,4.372)$ & $0.700(0.424,1.155)$ & $1.300(0.809,2.092)$ \\
\hline Middle school and above & $1.232(0.858,1.769)$ & $0.990(0.716,1.368)$ & $1.617(0.209,12.487)$ & $1.684(0.545,5.204)$ & $0.813(0.285,2.318)$ & $1.620(0.735,3.574)$ \\
\hline \multicolumn{7}{|l|}{ Marital status } \\
\hline Unmarried/divorced/widowed & $0.699(0.509,0.961)^{*}$ & $0.662(0.419,1.044)$ & $0.763(0.267,2.182)$ & $0.832(0.218,3.181)$ & $2.568(0.603,10.940)$ & $2.946(0.762,11.383)$ \\
\hline Labor force (yes) & $1.249(0.962,1.622)$ & $1.051(0.697,1.584)$ & $0.462(0.166,1.285)$ & $0.388(0.110,1.375)$ & $0.929(0.295,2.919)$ & $0.876(0.405,1.895)$ \\
\hline Chronic disease (yes) & $2.069(1.355,3.159)^{* *}$ & $2.089(1.450,3.011)^{* *}$ & $2.477(0.607,10.109)$ & $2.433(0.542,10.931)$ & $4.213(2.007,8.842)^{* *}$ & $5.759(2.943,11.268)^{* *}$ \\
\hline \multicolumn{7}{|l|}{ Per-capita income per year ${ }^{\text {b }}$} \\
\hline Group II & $0.960(0.654,1.407)$ & $1.155(0.638,2.091)$ & $1.349(0.300,9.109)$ & $2.516(0.805,7.862)$ & $1.016(0.454,2.273)$ & $1.187(0.358,3.940)$ \\
\hline Group III & $1.059(0.724,1.548)$ & $1.089(0.796,1.489)$ & $1.812(0.158,20.834)$ & $1.920(0.352,10.485)$ & $0.428(0.176,1.040)$ & $0.762(0.213,2.725)$ \\
\hline Group IV & $1.365(0.889,2.098)$ & $1.033(0.695,1.536)$ & $3.077(0.637,14.869)$ & $6.887(2.035,23.303)^{*}$ & $0.600(0.354,1.016)$ & $0.932(0.235,3.694)$ \\
\hline Group V & $1.502(0.709,3.186)$ & $1.103(0.640,1.900)$ & $3.282(0.273,39.525)$ & $2.206(0.219,22.238)$ & $0.323(0.147,0.708)^{*}$ & $0.464(0.115,1.877)$ \\
\hline
\end{tabular}

a The survey of leaving against medical advice started in 2006

${ }_{* *}^{\mathrm{b}}$ The per capita income per year was inflated to the year of 2014 using rural consumer price index and divided into five groups when sorted from low to high ( $\mathrm{V}$ is the highest)

${ }^{* *} p<0.01,{ }^{*} p<0.05$ 


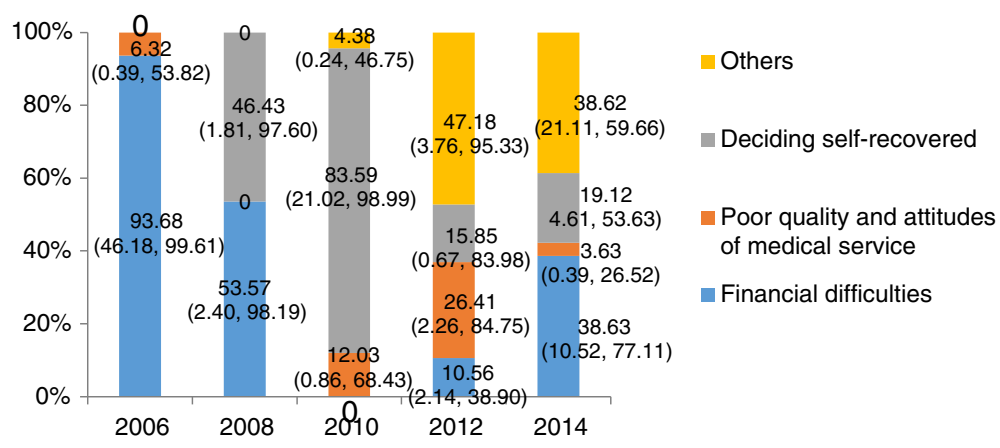

Fig. 1 The proportion of reporting reasons for elderly leaving against medical advice

implemented did not decrease, but rather increased by $15 \%$ [39]. Furthermore, in the present study, we found public hospital reform and essential medicine reform had not reduced hospitalization costs as well, because the annual average growth rate for per-capita hospitalization cost from 2003 to 2014 was $6.30 \%$. Above all, the effects of the two reforms on elderly hospitalization were limited.

In this study, we found that the elderly participants in 2012 (with a financial level of $\mathrm{V}, \mathrm{aOR}=2.295$ ) and in 2014 (with a financial level of $\mathrm{VI}, \mathrm{aOR}=3.045$ ) are more likely to be hospitalized, compared to ones in 2003 (financial level I); the rates of elderly left against medical advice was decreased by the financial levelV in 2012 $(\mathrm{aOR}=0.099)$; the elderly participants in 2014 (with a financial level of $\mathrm{VI}, \mathrm{aOR}=0.143$ ) are less likely to avoid being hospitalized. In the logistic regression models of hospitalization services for elderly, the financial level was taken as the proxy of NCMS, since the coverage of NCMS for elderly has been over $95 \%$ since 2006 in this study, and the number of non-NCMS group is too small for accurate comparison. Because the financing level of
NCMS had been increasing substantially and its annual average growth rate was $21.72 \%$ from 2003 to 2014 in Jiangxi, this would be an effective measurement for NCMS. These data indicated that the effects of NCMS policy on hospitalization services were evident in the most recent few years but limited in the first years, probably due to the lower financial level and reimbursement rate in these years. Although respondent income levels have also increased a lot in this decade, the variable of income level was not associated with the utilization of hospitalization services in the multivariate logistic regression analysis.

Meanwhile, the utilization of hospitalization service for elderly was also associated with the prevalence of chronic diseases $(\mathrm{aOR}=2.089)$. As the population ages, the system receives additional patients who are older adults with chronic diseases, which leads to more hospitalizations.

In addition, we found that the elderly suffering from chronic diseases were more likely to avoid being hospitalized even though their doctor advised treatment $(\mathrm{aOR}=5.759)$. This is consistent with the study

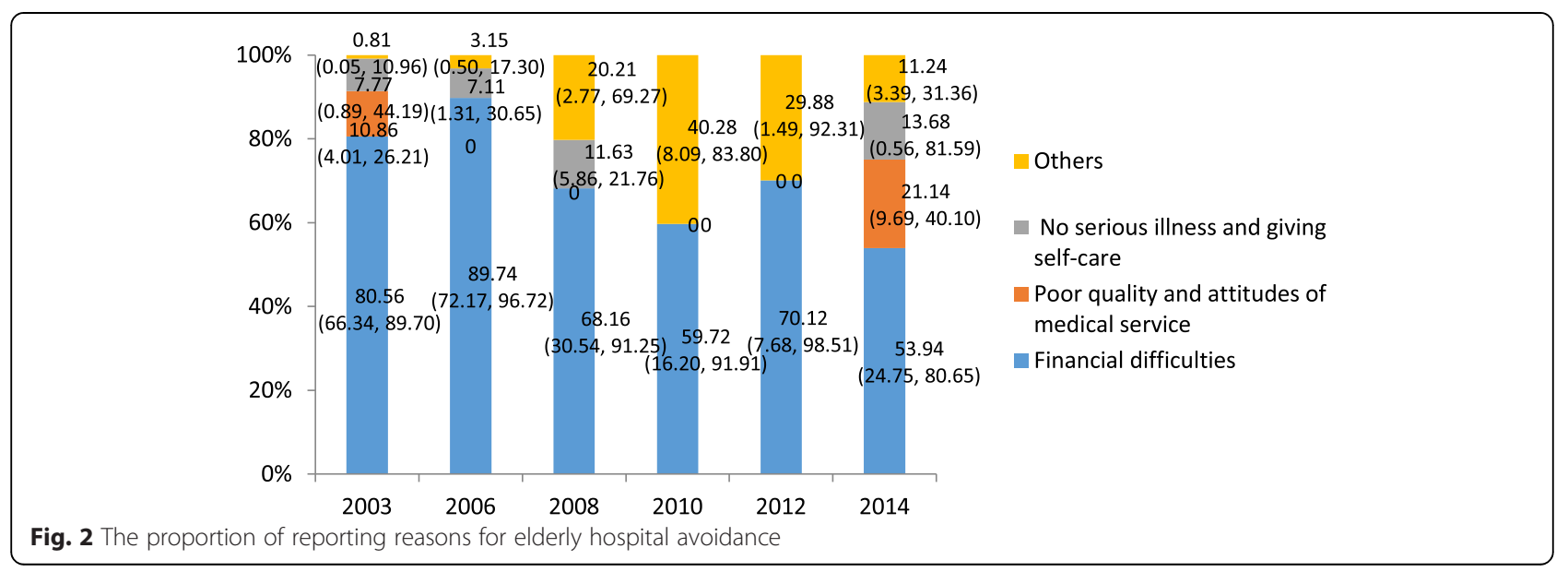


conducted in Chongqing [40], which observed that the elderly with chronic diseases affected the hospitalization utilization. The potential reason is that the elderly, owing to expensive medical cost and fewer economic resources, have no money to be hospitalized. The concordant result was found in this study: financial difficulty still was the primary reported reason for elderly hospital avoidance in all of the years examined. In addition, the proportion of Poor quality and attitudes of medical service among reasons of hospital avoidance in 2014 was relatively higher, potentially in that as people's living level improved these years, the demand for quality and attitudes of medical service might increase. The quality of medical service in the past may be the same as that in the present, or worse, but the people were poor before and the demand for being hospitalized could be not fulfilled, not to mention the demand for quality and attitudes of medical service. Furthermore, the elderly, who may have been suffering from chronic diseases for a longer time, took the disease status for granted and lost trust in the doctors, because of the poor quality of medical services.

Compared with the national level, the hospitalization rate for the elderly was $9.43 \%$, lower than the whole country for both the urban elderly population (19.36\%) and the rural elderly population (12.94\%) in 2008 [41]. The rate of elderly hospital avoidance was $35.60 \%$, higher than for the whole country in both the urban elderly population (23.8\%) and the rural elderly population (31.4 \%) in 2008 [41]. Although the utilization level of elderly hospital service improved gradually, the effects in rural areas of Jiangxi Province were significantly less than for the national level both in urban and rural areas. The potential explanation is that the funding for NCMS in Jiangxi province is lower than that in the provinces with higher economic scales. Moreover, the financial levels for NCMS in Jiangxi province is far lower than medical insurance for urban residing individuals in China and the reimbursement range is narrower, the type of reimbursable medicine being more limited and the amount of reimbursement being far lower [40] continue to pay more attention to the demand and utilization of elderly health services, especially for the elderly with chronic diseases, and should provide more medical assistance to elderly population with financial difficulties.

\section{Limitations}

Some data in our survey, like gross household income, were collected on the basis of personal recall and as such recall bias may serve as a limitation of the current study. Even so, several global surveys (e.g. the Behavioral Risk Factor Surveillance System in the
USA [42]) are also subject to recall bias. Thus, this is a common limitation in survey research. However, the response rates of all surveys were $100 \%$, maybe indicating non-response bias was not a significant issue. This is due in large part to the village leaders in each village guiding researchers to interview rural residents. At the same time, government support may lead to selection bias, but we had almost investigated all of households in the village, this bias may be not a significant issue.

There are three variable selection procedures in logistic regression, namely forward, backward and stepwise. Each variable selection procedures have limitations. As to forward technique, the introduction of the following variables would make the variables previously entered be insignificance. If using backward technique, the number of variables selected is more than the number using forward technique. However, if there is large number of independent variables or highly correlations between them, it will result in incorrect associations. Stepwise technique overcomes the limitations of the two techniques above, but that not to say it is the best way to select variables.

We were unable to investigate the exact same individuals in every year of the study. Thus, potential migratory flow within China should be taken into account when interpreting the results. However, we did measured changes in the same villages.

Myers index is a way of measuring the serious of investigators filling in questionnaire, namely no phenomenon of the accumulation within age of the tail when investigators filling in variable of age. However, it has no ability to illustrate other quality problems.

\section{Conclusion}

In rural areas of Jiangxi province, with the continued improvement of NCMS policy, the utilization of hospitalization health services for the rural elderly increased gradually, which demonstrated that the implementation of NCMS in Jiangxi province achieved positive effects. But the effects were significantly less than at the national level both in urban and rural areas, and cost-related barriers still were the primary reported reason given for limited access to in-patient services. Furthermore, in the multivariate logistic regression analysis, the factors that influenced elderly hospital admissions were the high level financial level of NCMS, and the prevalence of chronic diseases. Hence, the Chinese government should continue to pay more attention to the demand and utilization of elderly health services, especially for the elderly with chronic diseases, and should provide more medical assistance to elderly population with financial difficulties. 


\section{Appendix}

Table 4 Variable assignment of the potential factors of elderly hospitalization service

\begin{tabular}{|c|c|c|}
\hline Factors & Variable name & Factor assignment \\
\hline \multicolumn{3}{|l|}{ Dependent variables } \\
\hline Hospitalization & $Y_{1}$ & $1=$ Yes, $0=$ No(referent) \\
\hline Leaving against medical advice & $Y_{2}$ & $1=$ Yes, 0 = No(referent) \\
\hline Hospital avoidance & $Y_{3}$ & $1=$ Yes, $0=$ No(referent) \\
\hline \multicolumn{3}{|l|}{ Independent variables } \\
\hline \multirow[t]{6}{*}{ Per-capita financial level for $\mathrm{NCMS}^{\mathrm{a}}$} & $X_{1}, X_{2}$ & Level I(43Yuan)(referent): $X_{1}=0, X_{2}=0, X_{3}=0, X_{4}=0, X_{5}=0$ \\
\hline & $X_{3}, X_{4}, x_{5}$ & Level II(66Yuan,2006): $X_{1}=1, X_{2}=0, X_{3}=0, X_{4}=0, X_{5}=0$ \\
\hline & & Level III(123Yuan, 2008): $X_{1}=0, X_{2}=1, X_{3}=0, X_{4}=0, X_{5}=0$ \\
\hline & & Level IV(173Yuan, 2010): $X_{1}=0, X_{2}=0, X_{3}=1, X_{4}=0, X_{5}=0$ \\
\hline & & Level V(306Yuan, 2012): $X_{1}=0, X_{2}=0, X_{3}=0, X_{4}=1, X_{5}=0$ \\
\hline & & Level VI(370Yuan, 2014): $X_{1}=0, X_{2}=0, X_{3}=0, X_{4}=0, X_{5}=1$ \\
\hline Sex & $x_{6}$ & $1=$ Male, $0=$ Female(referent) \\
\hline \multirow[t]{3}{*}{ Age } & $x_{7}, x_{8}$ & $65 \sim$ (referent): $X_{7}=0, X_{8}=0$ \\
\hline & & $75 \sim: X_{7}=1, X_{8}=0$ \\
\hline & & $85 \sim: X_{7}=0, X_{8}=1$ \\
\hline Occupation & $X_{9}$ & 1 = No-farmer, 0 = Farmer(referent) \\
\hline \multirow[t]{3}{*}{ Educational level } & $x_{10}, x_{11}$ & Illiterate(referent): $X_{10}=0, X_{11}=0$ \\
\hline & & Elementary school: $X_{10}=1, X_{11}=0$ \\
\hline & & Middle school and above: $X_{10}=0, X_{11}=1$ \\
\hline Marital status & $x_{12}$ & $1=$ Unmarried/divorced/widowed, 0 = Married(referent) \\
\hline Labor force & $x_{13}$ & $1=$ Yes, 0 = No(referent) \\
\hline Chronic disease & $X_{14}$ & $1=$ Yes, $0=$ No(referent) \\
\hline \multirow[t]{5}{*}{ Per capita income per year ${ }^{\mathrm{b}}$} & $X_{15}, X_{16}$ & Group I(referent): $X_{15}=0, X_{16}=0, X_{17}=0, X_{18}=0$ \\
\hline & $\mathrm{X}_{17}, \mathrm{X}_{18}$ & Group II: $X_{15}=1, X_{16}=0, X_{17}=0, X_{18}=0$ \\
\hline & & Group III: $X_{15}=0, X_{16}=1, X_{17}=0, X_{18}=0$ \\
\hline & & Group IV: $X_{15}=0, X_{16}=0, X_{17}=1, X_{18}=0$ \\
\hline & & Group V: $X_{15}=0, X_{16}=0, X_{17}=1, X_{18}=0$ \\
\hline
\end{tabular}

a When the index of leaving against medical advice analyzed, the referent was 2006

${ }^{b}$ The per capita income per year was inflated to the year of 2014 using rural consumer price index and divided into five groups when sorted from low to high ( $\mathrm{V}$ is the highest)

\section{Additional files}

Additional file 1: Questionnaire 1. The questionnaire of farmer family health in Jiangxi Province. (DOCX $21.2 \mathrm{~kb}$ )

Additional file 2: Questionnaire 2. The questionnaire of medical service utilization and cost. (DOCX 22. kb)

Additional file 3: Overall sample. The raw data information about the overall sample, such as sex, age and so on. (DOCX $12 \mathrm{~kb}$ )

\section{Acknowledgements}

This study was supported by the Health Department of Jiangxi province, P. R. China. The lead agency is School of Public Health, Nanchang University. The collaborating agencies are Health Bureau of Luxi County, Wuyuan County and Xiushui County. We express our gratitude for the generous support of Health Department of Jiangxi province and Health Bureau of Luxi County, Wuyuan County and Xiushui County and the involvement of the officials from these bureaus in the survey of NRCMS. We also express our gratitude for the participation of the entire graduate students from 2003.

\section{Funding}

This research was supported by the Nation Natural Science Foundation of P.R.China (70763007).

\section{Availability of data and materials}

All data generated or analyzed during this study are included in this published article and its supplementary information files, but restrictions apply to the availability of these data, which were used under license for the current study, and so are not publicly available. Data are however available from the corresponding author on reasonable request (Additional file 3).

\section{Authors' contributions}

BP drafted the paper and carried out data analysis. ZY designed and overseen the project. JZ participated in data collection and analysis. WY and 
DC participated in translating results and in critically revised the manuscript for intellectual content. All authors approved the final draft of the manuscript.

\section{Competing interests}

The authors declare that they have no competing interests.

\section{Consent for publication \\ Not applicable.}

\section{Ethics approval and consent to participate}

The study was approved by the Nanchang University Institutional Review Board. All procedures were in accordance with the ethical standards of the Helsinki Declaration. Participants provided informed consent prior to data collection.

Received: 29 January 2016 Accepted: 5 August 2016

Published online: 24 August 2016

\section{References}

1. Press $Y$, Tandeter $H$, Romem $P$, Hazzan R, Farkash M. Depressive symptomatology as a risk factor for increased health service utilization among elderly patients in primary care. Arch Gerontol Geriatr. 2012;54:127-30.

2. Liu H-H, Li J-J. Aging and dyslipidemia: A review of potential mechanisms. Ageing Res Rev. 2015;19:43-52.

3. Yang Q. A study on the equity of elder health service in the experimental region of New-type rural cooperative medical System in Jiangxi Province. Nanchang University: Public health and Preventive Medicine; 2011.

4. National Statistics Bureau. China Statistical Yearbook 2014. Beijing: National Bureau of Statistics of China; 2015.

5. Liu LF, Tian WH, Yao HP. Utilization of health care services by elderly people with National Health Insurance in Taiwan: The heterogeneous health profile approach. Health Policy. 2012;108(2-3):246-55.

6. Milos V, Bondesson $\AA$, Magnusson M, Jakobsson U, Westerlund T, Midlöv P. Fall risk-increasing drugs and falls: a cross-sectional study among elderly patients in primary care. BMC Geriatr. 2014. doi:10.1186/1471-2318-14-40.

7. Zhang ZF, Zhou DJ, Zhu CY, Zhang G, Wan J, Xia J, Gong J. Investigation on health service demands and utilization of elderly aged 60 and over in WuHan. J Pub Health Pre Med. 2013;24:50-2.

8. Waters HR, Anderson GF, Mays J. Measuring financial protection in health in the United States. Health Policy. 2004;69:339-49.

9. Kim S, Kwon S. Has the National Health Insurance improved the inequality in the use of tertiary-care hospitals in Korea? Health Policy. 2014;118:377-85.

10. Liu X, Tang S, Yu B, Phuong NK, Yan F, Thien DD, Tolhurst R. Can rural health insurance improve equity in health care utilization? a comparison between China and Vietnam. Int J Equity Health. 2012;11:10.

11. George PP, Heng BH, De Castro Molina JA, Wong LY, Wei Lin N, Cheah J. Self-reported chronic diseases and health status and health service utilization-results from a community health survey in Singapore. Int J Equity Health. 2012;11:44.

12. Yang W. China's new cooperative medical scheme and equity in access to health care: evidence from a longitudinal household survey. Int J Equity Health. 2013;12:20

13. Center for Health Statistics and Information of $\mathrm{MOH}$. An Analysis Report of National Health Services Survey in 2003. Beijing: Xie He Medical University Press; 2004. p. 44-5.

14. Statistics Bureau of Jiangxi. Statistical Yearbook of Jiangxi 2014. Nanchang: Statistics Bureau of Jiangxi; 2015.

15. Wang X, He X, Zheng A, Ji X. The effects of China's New Cooperative Medical Scheme on accessibility and affordability of healthcare services: an empirical research in Liaoning Province. BMC Health Serv Res. 2014;14:388.

16. Cheng $L$, Liu $H$, Zhang $Y$, Shen $K$, Zeng $Y$. The impact of health insurance on health outcomes and spending of the elderly: evidence from China's New Cooperative Medical Scheme. Health Econ. 2015;24(6):672-91.

17. Hou Z, Van de Poel E, Van Doorslaer E, Yu B, Meng Q. Effects of NCMS on access to care and financial protection in China. Health Econ. 2014:23(8):917-34.

18. Shi L, Zhang D. China's New Rural Cooperative Medical Scheme and underutilization of medical care among adults over 45: evidence from CHARLS pilot data. J Rural Health. 2013;29:s51-61.
19. Zou J, Yang W, Cook DM, Yuan Z, Zhang L, Wang X. New cooperative medical financing policy and hospitalization in rural China: multi-stage cross-sectional surveys. Int health. 2016;8(1):59-66.

20. Yu B, Meng Q, Collins C, Tolhurst R, Tang S, Yan F, Bogg L, Liu X. How does the New Cooperative Medical Scheme influence health service utilization? A study in two provinces in rural China. BMC Health Serv Res. 2010;10:116.

21. Babiarz KS, Miller G, Yi H, Zhang L, Rozelle S. New evidence on the impact of China's New Rural Cooperative Medical Scheme and its implications for rural primary healthcare: multivariate difference-in-difference analysis. BMJ. 2010;341.

22. Lei $X$, Lin W. The new cooperative medical scheme in rural China: does more coverage mean more service and better health? Health Econ. 2009;18:S25-46.

23. Platt RW, Harper SB. Survey data with sampling weights: is there a" best" approach. Environ Res. 2013;120:143-4.

24. Whitmore R, Byron M, Clayton C, Thomas K, Zelon H, Pellizzari E, Lioy P, Quackenboss J. Sampling design, response rates, and analysis weights for the National Human Exposure Assessment Survey (NHEXAS) in EPA region 5. J Expo Anal Env Epid. 1998;9:369-80.

25. Potter FJ, lannacchione VG, Mosher WD, Mason RE, Kavee JD. Sample design, sampling weights, imputation, and variance estimation in the 1995 National Survey of Family Growth. Vital Health Stat 2. 1998;57(124):465-75.

26. Israel GD. Determining sample size. University of Florida Cooperative Extension Service, Institute of Food and Agriculture Sciences, EDIS. 1992.

27. Li L, Ye D. Epidemiology. Beijing: People's medical publishing house; 2011.

28. Lin H, Zhai F, Xue H, Ge K. Three population-age distribution indices of the samples of national nutrition survey in1992. J Hyg Res. 1996;25:57-61.

29. Yang L, Qin J, Jin M, Guo S, Liu J, Wang Z, Wang W, Tang J, Wei Z, Feng G. Sampling and quality control of the health services investigation in Xinjiang Shihezi University (Natural Science Edition). 2003;7:21-4.

30. Van Deusen PC, Heath LS. Weighted analysis methods for mapped plot forest inventory data: tables, regressions, maps and graphs. Forest Ecol Manag. 2010;260:1607-12.

31. Platt RW, Harper SB. Survey data with sampling weights: Is there a "best" approach? Environ Res. 2013;120:143-4.

32. Magee $L$, Robb AL, Burbidge JB. On the use of sampling weights when estimating regression models with survey data. J Econometrics. 1998;84:251-71.

33. Sun Z. Medical statistics. Beijing: People's medical publishing house; 2010.

34. Health and Family Planning Commission of Jiangxi province. Analysis report on the development of health industry in Jiangxi Province in 2007-2008. 2008. http://www.jxwst.gov.cn/tjsj/201012/t20101201_64110.htm. Accessed 16 Aug 2016.

35. Health and Family Planning Commission of Jiangxi province. Analysis report on the development of health industry in Jiangxi Province in 2014. 2015. http://www.jxwst.gov.cn/tjsj/201508/t20150826 403769.htm. Accessed 16 Aug 2016.

36. Hu H, Li Y, Li Y. Urban and rural differences, opulence, system fairness and the elderly health services utilization-the elderly hospital services utilization based on comparative analysis. Journal of guangxi economic management cadre college. 2011;23:20-8.

37. Health and family planning commission of Jiangxi provincial. An analysis report of the developing status of health family planning career in 2013 in Jiangxi province. 2014. http://www.jxwst.gov.cn/tjsj/201408/t20140805_ 333205.htm. Accessed 16 Aug 2016

38. Health and family planning commission of Jiangxi provincial. An analysis report of the developing status of health family planning career in 20082009 in Jiangxi province. 2010. http://www.jxwst.gov.cn/tjsj/201012/ t20101201 64111.htm. Accessed 16 Aug 2016

39. Du N, Xu C, Shu Y, Liu G. Impacts of the implementation of an essential medicines programme on medicine pricing and utilization-empirical research based on data coverage. China Econ Stud. 2015;302(1):88-99.

40. He J, Zhou Y, Zou Q, Li Y, Zhong X. Hospitalization utilization and its influencing factors among older persons in Chongqing city. China Jounral Public Health. 2014;30:141-3.

41. Center for Health Statistics and Information of $\mathrm{MOH}$. An Analysis Report of the Fourth National Health Services Survey in 2008 in China. National Health and Family Planning Commission; 2010. http://www.moh.gov.cn/ mohwsbwstjxxzx/s8211/201009/49165.shtml. Accessed 16 Aug 2016.

42. Centers for Disease Control and Prevention (CDC). Behavioral Risk Factor Surveillance System Survey Data. Atlanta: U.S. Department of Health and Human Services, Centers for Disease Control and Prevention; 1995. http:// www.cdc.gov/brfss/. Accessed 16 Aug 2016. 